\title{
A critical look at the value of clinical examination in polytraumatized patients
}

\author{
Pliske $\mathbf{G}^{1 *}$, Lucas $\mathrm{B}^{1}$, Schmidt $\mathrm{S}^{2}$, Hausler-Pliske $\mathrm{I}^{3}$, Walcher $\mathrm{F}^{1}$ and Piatek $\mathrm{S}^{1}$ \\ ${ }^{1}$ Department of Traumatology, Otto-von-Guericke-University, Magdeburg, Germany \\ ${ }^{2}$ Institute of Legal Medicine, Martin-Luther-University, Halle-Wittenberg, Germany \\ ${ }^{3}$ Department of General, Visceral, Vascular and Transplant Surgery, Otto-von-Guericke-University, Magdeburg, Germany
}

\begin{abstract}
Background and question: The Advanced Trauma Life Support (ATLS) offers a concept for the treatment of severely injured patients. In the so-called "primary survey", the patients are first examined clinically by "A-E". Subsequently, a CT scan will be performed to make accurate diagnosis. But what benefit do the clinical examinations have if a CT is performed immediately afterwards? Are the examinations just a waste of time or do they provide important information?

Method: Systematic mesh-term research on pubmed.com with 62 studies to compare the latest literature on the value of clinical examinations with ATLS recommendations.

Results: Relevant airway problems can directly threaten the patient and should be quickly diagnosed and fixed. Clinical examination of the cervical spine has poor sensitivity and should be avoided. The examination for hemato-/pneumothorax after blunt and penetration trauma shows a middle sensitivity but a good negative and positive predictive value. If a serious thoracic injury is suspected, a thoracic puncture or a chest tube should be done. Internal bleeding is difficult to diagnose clinically and often cannot be treated without surgical or radiological intervention. The CT scan should be done promptly and time delays by numerous clinical examinations should be avoided. Unstable pelvic fractures can be well diagnosed, depending on the technique used. If the pelvis is unstable a pelvic sling should be applied to avoid a "C-problem". Intracranial and spinal injuries cannot be diagnosed clinically. If suspected, a CT scan should be performed. During a prolonged examination of the undressed patient, the body temperature can decrease, which may be accompanied by deterioration in blood coagulation.
\end{abstract}

Conclusion: The extent of the physical examination in the shock room, immediately before the CT scan, should be taken individually. With exception of airway and breathing problems, most diagnoses can only be reliably detected and treated after the CT scan..

\section{Background}

The "Advanced Trauma Life Support" (ATLS) is a systematic approach of early care for polytraumatized patients invented by the American College of Surgeons nearly 30 years ago. This concept should enable one physician (male/female) and one nurse (male/female) to examine and treat a multiple-injured patient without missing significant findings. The focus is on the examination and treatment of the most bleak accident consequences. According to the motto "treat first what kills first" the pathologies, which endanger the patient directly should be treated first.

This systematic methodology for assessment and initial stabilization of the polytraumatized patients consists of five categories from $\mathrm{AE}$ :

$\mathrm{A}=$ Airway; includes airway management and the immobilization of the cervical spine via Stiffneck

$\mathrm{B}=$ Breathing; includes thoracic injuries and gas exchange disorders like pneumothorax and hematothorax

$\mathrm{C}=$ Circulation; includes circulatory stabilization and the treatment of critical bleeding

$\mathrm{D}=$ Disabilities; includes neurological and neurosurgical consequences of the accident

$\mathrm{E}=$ Exposure; includes the undressing of the patient, body temperature, and fracture/wound management
As part of ATLS concept, points A - E has to be examined sequentially within 10 minutes in the so-called "primary survey“. If a problem occurs at one of these points, first of all this problem has to be resolved before continuing the examination and treatment. Subsequent to the primary survey, a polytrauma computed tomography (CT) scan should be performed to get further and more accurate findings.

Depending on the severity of a problem found in the primary survey and its treatment, the primary survey may be significantly prolonged. As a result, the CT scan is delayed, and other relevant trauma consequences can be detected late.

There is no question that in case of endangered airway, this must be secured first. But what about the value of other examination findings, for example for thorax and pelvis? Are the clinical findings made in the physical examination worth the time you have to invest?

${ }^{*}$ Correspondence to: Gerald Pliske, MD, Department of Traumatology, Ottovon-Guericke-University, Leipziger Strabe 44, 39120 Magdeburg, Germany, E-mail: gerald.pliske@med.ovgu.de

Key words: polytrauma, clinical examination, ATLS, emergency department, shock room

Received: October 11, 2018; Accepted: October 23, 2018; Published: October 25,2018 


\section{Question}

How good and valuable is the clinical examination of the patient in the emergency department (ED), if only a short time later a CT scan with contrast agent will be performed? Are these findings so valuable that they justify delaying CT by several minutes? How reliable are the clinical symptoms for diagnosis?

\section{Method}

In order to answer the question of the value of clinical symptoms in the early care of multiple-injured patients, the ATLS recommendations for the points $\mathrm{A}-\mathrm{E}$ were compared with the current literature. For this purpose, a systematic search on pubmed.com under the following mesh terms was performed: "Thoracic Injuries/diagnosis", Abdominal Trauma/Injury”, Head Trauma/Injury”, Neck Trauma/Injury”, "Pelvic Trauma/Injury", Temperature Trauma”, Extremity Trauma”, Spinal cord/ column Injury" and "Physical Examination". A total of 62 publications were evaluated from September 2000 to September 2018.

\section{Results}

\section{Airway and immobilization of the cervical spine}

In a polytraumatized patient, a relevant A-problem may arise from aspirated or penetrating foreign objects like fractured teeth or knifes etc. [1-3]. Clinical symptoms include acute respiratory failure, dyspnoea, wheezing or coughing during spontaneous breathing or an increased ventilation pressure in the intubated patient [4]. A jigging over the obstructed lung field can be found at the auscultation.

In addition to airway obstructions by foreign objects a midface fracture or a dislocated vertebra can pose a threat to the airway [5]. Patients with midface fracture may also need a secured airway. These patients often have an initial loss of consciousness, a Glasgow coma scale (GCS) of $\leq 8$ or positive physical examination findings [6]. Harrington et al. (2018) evaluated the Wisconsin's Clinical Criteria for maxillofacial fractures. The sensitivity for $\geq 1$ of the 5 clinical criteria (bony step off or instability, periorbital ecchymosis, malocclusion, tooth absence, and GCS) was $81 \%$. The absence of all 5 criteria showed a negative predictive value of $60 \%$ [7]. Diagnosis of maxilla fracture could easily be missed in children because of their limited cooperation with clinical examination [8].

Goode et al. (2014) investigated the value of the clinical examination of the cervical spine for fractures and figured out that the sensitivity for patients over 65 years is only $66 \%$ and for patients under 65 years $84 \%$ [9].

Libermann et al. (2014) reported an overall sensitivity and specificity for the ability of the initial clinical examination of the cervical spine to predict radiological abnormality of $60.9 \%$ and $71.3 \%$, respectively $\mathrm{NPV}=82.9 \%$ in alcoholised patients. In alcoholised patients with GCS $\geq 13$, sensitivity, specificity, and NPV for CS tenderness and radiological abnormality were $71.9 \%, 67.7 \%$ and $87.8 \%$ [10].

By using the 18 items of NEXUS and Canadian c-spine criteria the sensitivity of the clinical examination can be raised up to $100 \%$ but poor specificity $(0.62 \%)$. By using only the seven most associated criteria with fracture (midline tenderness, GCS less than 15, age $\geq 65$ years, paraesthesia, rollover motor vehicle collision, ejected, never in sitting position in ED) the sensitivity is $99.07 \%$, positive predictive value (PPV) $6.95 \%$, specificity $11.57 \%$, and the negative predictive value (NPV) 99,47\% [11].

\section{Breathing}

Thoracic injuries occur especially in high energy trauma like vehicle accidents or fall from greater altitude [12-14]. The most common injuries after thoracic trauma are rib fractures, pneumo- and/ or hematothorax, and pulmonary contusions. In polytrauma patients the abdominal visceral injury is the most associated injury with rip fracture [14].

Lavingia et al. (2015) investigated the need for thoracic CT scan for patients who fall from standing. All patients with findings in CT scan showed symptoms at the physical examination. Patients without clinical symptoms never had a positive radiographic finding for significant thoracic injury like fractures or pneumothorax (NPV 100\%) [15].

But the physical findings like subcutaneous emphysema only have low sensitivity $(12-25 \%)$ [16]. For thoracic pain after blunt trauma the sensitivity for pneumo- or hematothorax is 57.1\% [17] (Figure 1 and 2). Only the auscultation seems to be a reliable clinical parameter for

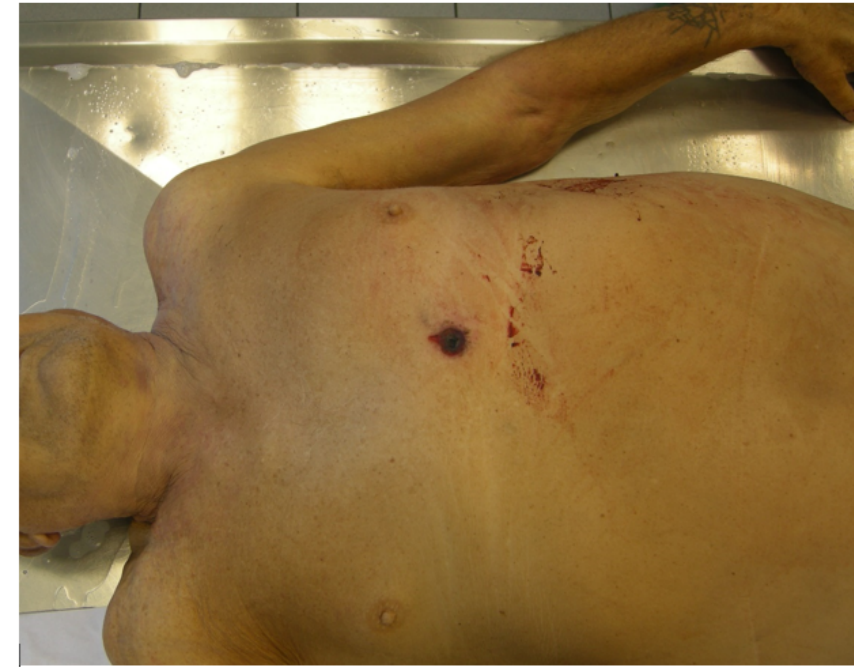

Figure 1. Shot wound after a shot in suicidal intent. Subcutaneous emphysema and pneumothorax were clinically unrecognizable

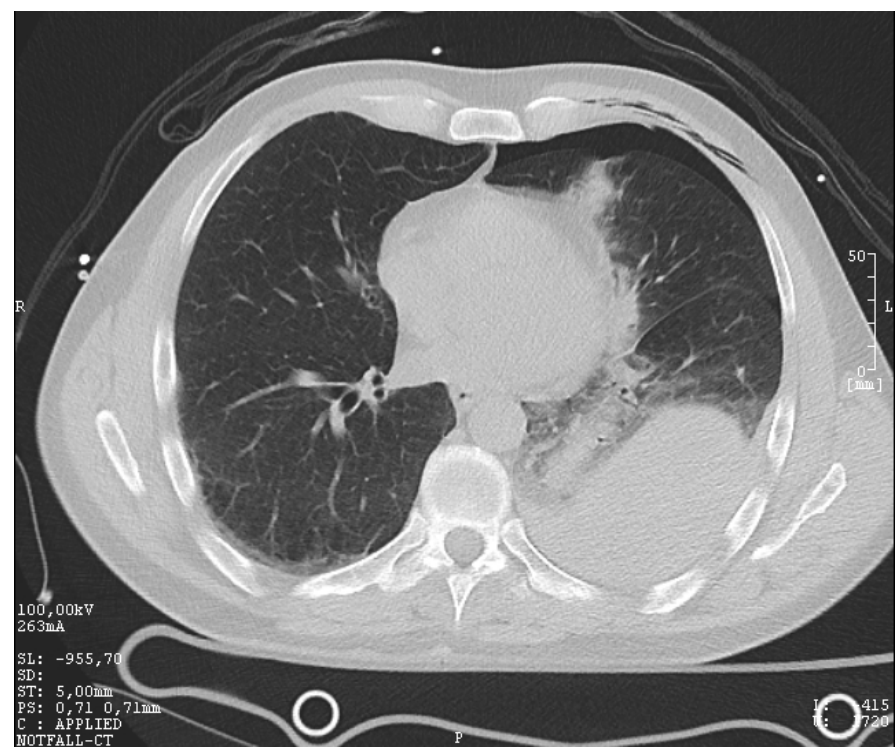

Figure 2. CT scan from patient with shot wound. The CT shows the findings of emphysema and pneumothorax on the left side 
detecting a pneumo- or hematothorax. The sensitivity for auscultation within blunt thoracic trauma is up to $100 \%$. The NPV for auscultation, pain, and tachypnea within blunt and penetrating thoracic trauma is $99 \%$ and over 90\% [17]. Kong et al. (2015) described a sensitivity of physical examination for significant pathology findings of $68 \%$, specificity $86 \%$, the PPV 94\%, and NPV 47\% in penetrating thoracic trauma. Sensitivity and specificity of physical examination for pneumothorax was $59 \%$ and 96\%, for hematothorax 79\% and 96\%. Physical examination was overall clinical status, respiratory rate, oxygen saturation, tracheal deviation, chest expansion, percussion note and auscultation findings [18].

Abdulrahman et al. (2015) evaluated the value of clinical examination, chest $\mathrm{x}$-ray, and EFAST sonography for pneumothorax with a sensitivity of $41.3 \%, 10.7 \%$, and $42.7 \%$, a specificity of $91.2 \%$, $98.9 \%$, and $98.1 \%$, a NPV of $39.7 \%, 57.1 \%$, and $76.2 \%$, and a PPV of 91.7\%, 88.7\%, and 92.4\% [19] (Table 1).

With the help of a CT scan, a reliable statement can be made about injury to internal organs in penetrating thoracic injuries. The sensitivity, specificity and accuracy of the CT scan for internal injuries are $91 \%$ [20].

\section{Circulation}

Chest: In addition to hematothorax, cardiovascular disorders that are relevant to the circulatory system may occur in blunt chest trauma. These cardiovascular disorders appear as arrhythmias, mainly tachycardia, cardiac murmurs or hypotension, can be alarm signals for cardiac trauma, but are non-specific [21]. Heavy chest trauma often shows Type II (blunt cardiac injury with heart block or ischemic changes without cardiac failure) or Type IV (Blunt or penetrating cardiac injury with septal rupture, pulmonary or tricuspid valvular incompetence, papillary muscle dysfunction, or distal coronary arterial occlusion producing cardiac failure) injuries of the Organ Injury Scale. Atrial- or ventricular arrhythmias occur in $34.0 \%$ respectively $38.3 \%$ and are also unspecific and hard to find within physical examination [22]. At the moment there is no gold standard for the evaluation of cardiac disorders in the context of chest trauma [23].

Patients with aortic injuries following blunt trauma are often inconspicuous in clinical examination [24]. In physical examination of patients with blunt chest trauma and aortic injury, only $10 \%$ shows crepitation and $16.7 \%$ shows subcutaneous emphysema as an unspecific consequence of accompanying injuries. The most common concomitant and clinically recoverable injuries are rib fractures (93.4\%), pneumothorax (66.7\%), and hematothorax (43.4\%) [25].

Table 1. Value of clinical signs for thoracic injury (hemato-/pneumothorax)

\begin{tabular}{|l|l|l|l|l|}
\hline & Sensitivity & Specificity & PPV & NPV \\
\hline Bokhari, 2002 & & & & \\
\hline - Auscultation (blunt trauma) & $100.00 \%$ & $99.8 \%$ & $87.5 \%$ & $100 \%$ \\
\hline - Pain/tenderness (blunt trauma) & $57.1 \%$ & $78.6 \%$ & $3.5 \%$ & $99.3 \%$ \\
\hline - Tachypnea (blunt trauma) & $42.8 \%$ & $99.6 \%$ & $60.0 \%$ & $99.2 \%$ \\
\hline - Ausculatation (penetrating trauma) & $50.0 \%$ & $100 \%$ & $100 \%$ & $91.4 \%$ \\
\hline - Pain/tenderness (penetrating trauma) & $25.00 \%$ & $91.5 \%$ & $35.3 \%$ & $86.8 \%$ \\
\hline - Tachypnea (penetrating trauma) & $31.8 \%$ & $99.2 \%$ & $87.5 \%$ & $89.7 \%$ \\
\hline Kong,2015 & & & & \\
\hline $\begin{array}{l}\text { - Physical examination of penetrating } \\
\text { wounds }\end{array}$ & $68.00 \%$ & $86.00 \%$ & $94.00 \%$ & $47.00 \%$ \\
\hline \begin{tabular}{l} 
Abdulrahman, 2015 \\
\hline - Clinical examination
\end{tabular} & $41.3 \%$ & $91.2 \%$ & $39.7 \%$ & $91.7 \%$ \\
\hline \multicolumn{2}{|l|}{ PPV positive predictive value; NPV = negative predictive value } & & \\
\hline
\end{tabular}

\section{Abdomen}

Patients with blunt abdominal trauma, categorized as low-risk patients for intraabdominal injury, have a very low risk of intraabdominal injury. Of 237 patients who have all met low-risk criteria (no intoxication, no hypotension or tachycardia, no abdominal pain or tenderness, no hematuria, and no distracting injury), no patient has shown an intra-abdominal injury or has died [26].

Moura et al. (2017) evaluated five signs for abdominal injury which are hemodynamic stability, normal neurologic exam at admission, normal physical exam of the chest at admission, normal abdomen and pelvis physical exam at admission and absence of distracting lesions. Two of 2031 patients with all clinical symptoms and examinations negative showed an intra-abdominal lesion. Sonography identified 71 of 75 patients with intra-abdominal lesions. When all clinical criteria and ultrasound are negative, the risk for intra-abdominal lesions after blunt trauma is low [27]. But a negative CT scan finding in asymptomatic patients with blunt abdominal trauma can safely rule out an intraabdominal injury [28].

In a study from Firetto et al. (2018), 34 of 831 patients who had a blunt abdominal trauma and had unspecific clinical symptoms showed a blunt bowel and/or mesenteric injury in CT scan. Sensitivity and specificity for abdominal pain and guarding is $57.18 \% / 53.85 \%$ and $38.1 \%$ / 100.0\% [29]. Lavingia et al. (2015) described a NPV of $100 \%$ for abdominal symptoms for patients with abdominal injury, intraabdominal hematoma, and hollow viscus injury, aortic or urologic injury [15]. Bladder perforation is often difficult to differentiate from other reasons of abdominal pain [30].

\section{Pelvic}

The second leading traumatic cause of death is the pelvic injury. The mortality in patients with pelvic injury and shock symptoms is $30-50 \%$ [31]. The sensitivity of the clinical signs of a pelvic injury is $39.75 \%$, while specificity is $100 \%$. The PPV and NPV are $100 \%$ and $10 \%$ [32]. Clinical symptoms of a pelvic fracture can be pelvic pain/ tenderness, sacrum-/coccyxpain or tenderness, the straight leg raising test or missing of other distracting pain. The most meaningful criterion is the lack of pelvic pain (sensitivity $91.8 \%$ and specificity $94.2 \%$ ) [32]. The study of Bolt et al. (2018) confirms the importance of the straight leg raise and the pelvis pain. Patients with blunt pelvic trauma, GCS 15, and pelvic fracture always showed a positive straight leg raise test and pelvic pain (sensitivity and NPV $=100 \%)$ [33].

A study from Pehle et al. (2003) reported that the clinical stability tests for pelvic fractures with distraction, compression, and traction only shows a sensitivity of $44.1 \%$. 22 Patients with stabile pelvic in clinical examination had an unstable pelvic fracture (AO type B or C) in CT scan. However, if the results of the pelvic stability tests are positive, the PPV is about $96 \%$ [34]. In another study, the sensitivity of the clinical examination for unstable pelvic fractures is only $26 \%$ [35] (Table 2).

Polytraumatized children should undergo CT scans to rule out a pelvic fracture. In a study with 1433 patients aged $\leq 17$ years with pelvic fracture only $84.6 \%$ got a CT scan [36].

From the outside, the morphology of the pelvic fracture as well as possible sources of bleeding cannot be evaluated. An uncertain sign of concomitant vascular injury in pelvic fractures is hypotension. Patients with external iliac artery branch injuries were significantly associated with hemodynamic instability, when compared to those without external iliac artery branch injuries [37]. 


\section{Disabilities}

Head: High altitude falls, traffic accidents or attacks with various weapons can cause skull fractures and intracranial hemorrhages. Outer head injuries do not always correlate with intracranial findings. Symptoms of intracranial injury or skull fractures can also occur with time delay.

In a study from Solai et al. (2018) the researchers reported on 28 patients with basilar skull fracture to check the value of early and late (within 48h) clinical symptoms of these fracture. Clinical symptoms were raccoon eyes, Battle's sign, otorrhea and rhinorrhea (Figure 3 and 4). These early and late symptoms hat an accuracy of $55.9 \%$ vs $43.3 \%$, specificity of $52.8 \%$ vs $30.5 \%$, and positive predictive value of $24.7 \%$ vs $27.1 \%[38]$.

Only $23-41 \%$ of patients with traumatic brain injuries also have severe external head injuries However, these patients have higher mortality and morbidity than patients with brain injuries without external head injuries. Extracranial injuries are therefore a prognostic factor for patients with intracranial injuries [39].

Table 2. Value of clinical signs for pelvic fracture

\begin{tabular}{|l|c|c|c|c|}
\hline & Sensitivity & Specificity & PPV & NPV \\
\hline Majidinejad, 2018 & & & & \\
\hline - No pelvic pain or tenderness & $91.86 \%$ & $94.20 \%$ & $99.6 \%$ & $43.9 \%$ \\
\hline - Ability to active straight leg rising & $72.30 \%$ & $91.07 \%$ & $99.2 \%$ & $18.2 \%$ \\
\hline Shlamovitz, 2009 (unstable fractures) & & & & \\
\hline - Pelvic pain and tenderness & $100 \%$ & $93.00 \%$ & & \\
\hline - Pelvic deformity & $55.00 \%$ & $97.00 \%$ & & \\
\hline Shlamovitz, 2009 (stable fractures) & & & & \\
\hline - Pelvic pain and tenderness & $74.00 \%$ & $97.00 \%$ & & \\
\hline - Pelvic deformity & $30.00 \%$ & $98.00 \%$ & & \\
\hline Pehle, 2003 & & & & \\
\hline - manual stability test & $44.1 \%$ & $99.7 \%$ & $96.00 \%$ & $93.3 \%$ \\
\hline \multicolumn{2}{|l|}{} & & & \\
\hline PPV = positive predictive value; NPV = negative predictive value & & \\
\hline
\end{tabular}

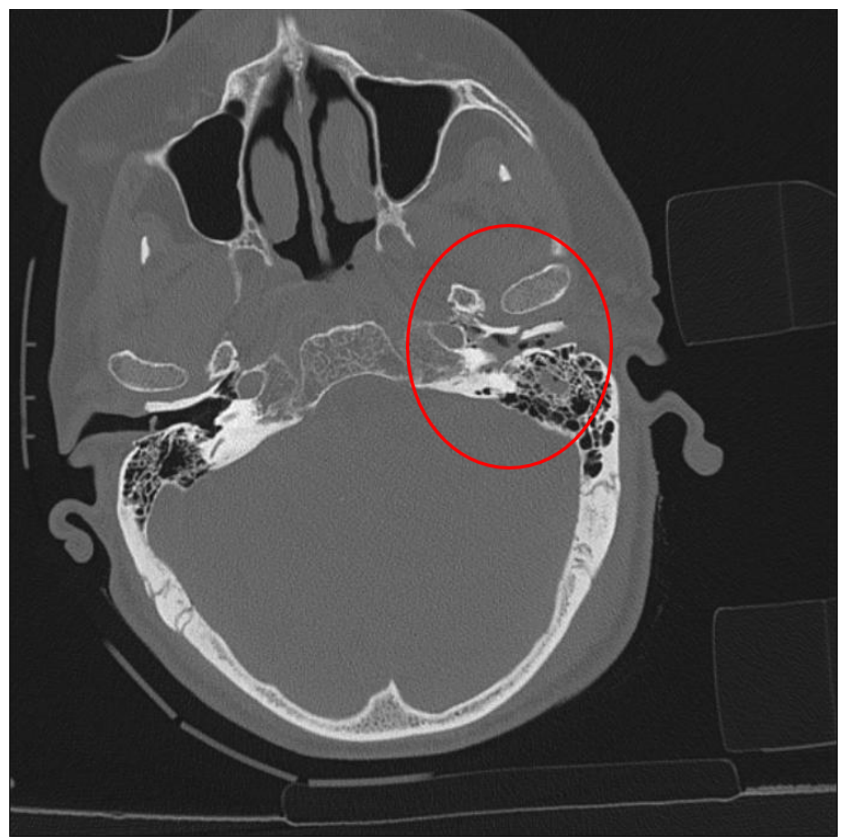

Figure 3. CT scan of the head of a patient after a traffic accident with a temporal bone left (red circle)

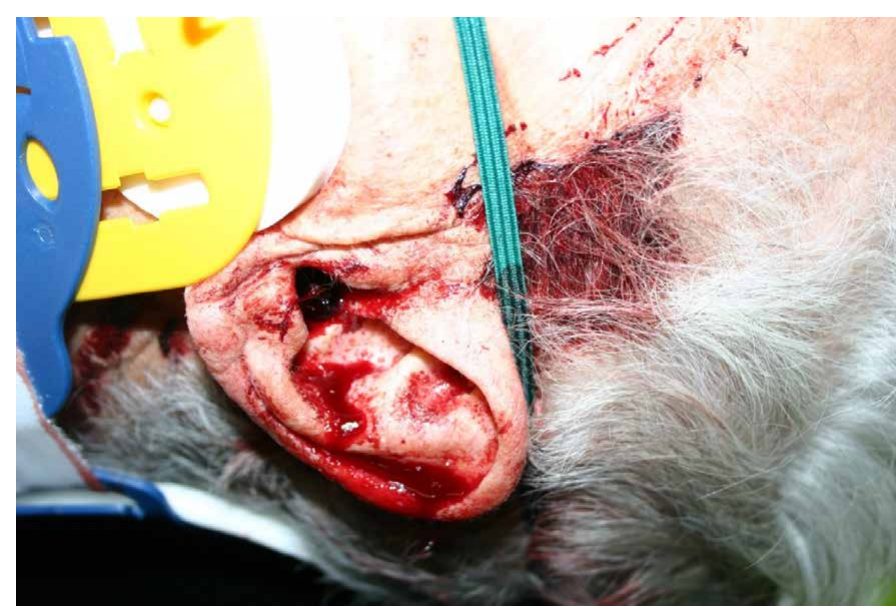

Figure 4. Clinical image of the patient with the fracture of the petrous bone. You can see an otorhea as an indication of a skull base fracture

Even minor head injuries in combination with oral anticoagulants can have a negative outcome. In a systematic review with 346 patients the rate of adverse outcome after mild head injury in combination with oral anticoagulants ranged from $0.0-8.3 \%$ [40].

Thoracolumbar spine: The clinical examination of patients with thoracolumbar spine injuries alone does not seem to be sufficiently certain. In a study of 666 patients examined, with a total of 56 thoracolumbar spine fractures, no pathological findings were found in the clinical examination in 29 patients (52\%). The sensitivity and specificity of the clinical examination for fractures in the thoracolumbar spine is thus $48.2 \%$ and $84.9 \%$ [ 41 ].

For sternum fractures, special attention must be paid to fractures of the thoracic spine. If a sternal fracture occurs in combination with thoracic spine fracture, the chance for an unstable AO type A or B fracture is up to $62.5 \%$. And even the chance of an unstable AO type $\mathrm{C}$ fracture is increased if the sternum and the thoracic spine fracture are at the same height [42].

\section{Exposure}

Body temperature: In trauma patients, body temperature control is crucial for the optimal function of blood clotting. In patients with cardiac arrest, hypothermia of $33^{\circ} \mathrm{C}$ has no negative influence on blood clotting, frequency of adverse bleeding or thrombotic events [43]. Significant changes in blood clotting could be observed when body temperature of healthy volunteers is $\leq 32^{\circ} \mathrm{C}$ or $\geq 37^{\circ} \mathrm{C}[44]$.

But in trauma patients a loss of body temperature should be avoided and treated as well as acidema or mass infusion [45]. Time to clot formation increased and fibrin cross-linking decreased in polytraumatized patients as body temperature decreased. Polytraumatized patients are more hypercoagulable than healthy subjects at decreased body temperature [46]. Also, a hypercoagulability could be observed in healthy volunteers with an elevated body temperature of $1.3^{\circ} \mathrm{C}-1.5^{\circ} \mathrm{C}$ [47]. Therefore, the body temperature should be maintained in a range between $33^{\circ} \mathrm{C}$ and $37^{\circ} \mathrm{C}$.

\section{Fracture and wound management}

Exact examination and treatment of soft tissue trauma and fractures is often part of the secondary survey. While these injuries may look dramatic, they rarely pose an immediate threat to the patient's life [48]. An open long bone fracture with uncontrollable bleeding or unstable 
pelvic fractures with hemodynamic instability are indications for immediate intervention [49]. The care of smaller fractures can be done as part of the secondary survey and is usually not time critical.

\section{Conclusion}

In the treatment of a seriously injured patient in the shock room, depending on the condition of the patient, hurry is required. The ATLS guidelines provide good recommendations for a thorough examination and treatment of a polytraumatized patient. Initially, a primary survey is recommended during the first ten minutes, during which the patient is examined from "A-E" and relevant findings are treated immediately. Subsequently, a polytrauma CT should be performed.

The current literature contains numerous studies describing the value of clinical investigations of traumatized patients in the ER. These studies investigated different types of injury's and clinical examinations and often describe sensitivity, specificity and PV of these methods. Sometimes, depending on the location and type of injury, a clinical examination immediately before the CT scan seems to be not useful. For the item "Airway and immobilization of the cervical spine" applies that problems in the airway management can be easily examined and have to be fixed immediately [2-4]. The separate investigation of the cervical spine, however, does not seem to provide sufficiently reliable findings and therefore appears not useful. This is also true for thoracolumbar spine [41-42]. Prophylactic immobilization of the cervical spine appears sufficient until CT scan [9-11].

Clinical findings for "Breathing" like subcutaneous emphysema or auscultatory findings and even the sonography only have middle sensitivity [16-18]. However, as a B-problem can quickly become life-threatening, an exploratory-clinically examination by means of auscultation and palpation should be done. The guidelines therefore recommend the use of a pleural puncture and / or the installation of a chest tube if there is a suitable accident mechanism and clinical suspicion of hemato-/pneumothorax [50]. CT scan is still the gold standard for the diagnosis of hemato-/pneumothorax.

Traumatic injuries of the heart, aorta or abdominal organs are poorly detectable be clinical examination $[22,24,27]$. Only CT brings a safe diagnosis that forms the basis for causal surgical or interventional therapy [28-29]. Depending on the examination method, a pelvic fracture can be clinically diagnosed and a possible bleeding can be provisionally treated by using a pelvic sling. For unstable patients with a "C problem", a CT scan should be performed as soon as possible [32].

Acute "D problems" may include anisocoria, vomiting, neurological deficits, or decreased GCS, and therefore the suspicion of an intracranial injury can often be asked. Clinical signs like raccoon eyes, Battle's sign, otorrhea and rhinorrhea are hints for a skull fracture but have a middle sensitivity and specificity and low positive predictive value [38]. External head injuries often do not correlate with the intracranial findings and the symptoms often appear only in temporal interval.

To avoid an "E-problem" that can arise due to the undressing of the patient and can result in a hyper- or hypocoagulability, the body temperature should be kept constant between $33-37^{\circ} \mathrm{C}$ [45-46].

$\mathrm{X}$-ray diagnosis of smaller fractures can be performed after the primary survey and is often not time-critical. Critical bleeding in the unstable patient, which can be treated externally without additional diagnostics, should be treated. Otherwise, the CT is groundbreaking for the diagnosis of (internal) bleeding [48-49].

The decision on how much clinical diagnostics will be performed before running the CT scan in the emergency department depends on the patient's injury pattern and condition and should be individually assessed. With exception of airway and breathing problems, most diagnoses can only be reliably detected and treated after the CT scan.

\section{Conflicts of Interest}

The authors declare that there are no conflicts of interests. There are no non-financial competing interests to declare in relation to this manuscript.

\section{References}

1. Casap N, Alterman M, Lieberman S, Zeltser R (2011) Enigma of missing teeth in maxillofacial trauma. J Oral Maxillofac Surg 69: 1421-1429. [Crossref]

2. Hajiioannou J, Sioka E, Koukoura O, Bizakis J (2018) Subcutaneous emphysema to the head and neck: an unlikely traumatic origin. BMJ Case Rep 2018. [Crossref]

3. Voss JO, Thieme N, Doll C, Hartwig S, Adolphs N, et al. (2018) Penetrating foreign bodies in head and neck trauma: A surgical challenge. Craniomaxillofacial Trauma \& Reconstruction 11: 172-182.

4. Sehgal IS, Dhooria S, Ram B, Singh N, Aggarwal AN, et al. (2015) Foreign body inhalation in the adult population: Experience of 25,998 bronchoscopies and systematic review of the literature. Respiratory Care 60: 1438-1448.

5. Navarrete-Sanchez I, Garcia-Delgado M (2012) A Foreign body in the upper airway. A vertebra in an unusual location. Medicina Intensiva 36: 599.

6. Huang LK, Wang HH, Tu HF, Fu CY (2017) Simultaneous head and facial computed tomography scans for assessing facial fractures in patients with traumatic brain injury. Injury 48: 1417-1422. [Crossref]

7. Harrington AW, Pei KY, Assi R, Davis KA (2018) External validation of university of wisconsin's clinical criteria for obtaining maxillofacial computed tomography in trauma. Journal of Craniofacial Surgery 29: 167-170.

8. Wang Y, Kang P, Gong YP, Zhai XY, Li Q, et al. (2018) Clinical analysis of 314 children with maxillofacial fracture. Zhonghua Kou Qiang Yi Xue Za Zhi 53: 555-557. [Crossref]

9. Goode T, Young A, Wilson SP, Katzen J, Wolfe LG, et al. (2014) Evaluation of cervical spine fracture in the elderly: can we trust our physical examination? The American Surgeon 80: 182-184.

10. Liberman M, Farooki N, Lavoie A, Mulder DS, Sampalis JS, et al. (2005) Clinical evaluation of the spine in the intoxicated blunt trauma patient. Injury 36: 519-525.

11. Duane TM, Young A, Mayglothling J, Wilson SP, Weber WF, et al. (2013) CT for all or selective approach? Who really needs a cervical spine CT after blunt trauma. Journal of Trauma and Acute Care Surgery 74: 1098-1101.

12. Bambach MR, Mitchell RJ (2014) The rising burden of serious thoracic trauma sustained by motorcyclists in road traffic crashes. Accident Analysis and Prevention 62: $248-258$

13. Parreira JG, Matar MR, Torres AL, Perlingeiro JA, Solda SC, et al. (2014) Comparative analysis between identified injuries of victims of fall from height and other mechanisms of closed trauma. Revista do Colegio Brasileira de Cirurgioes 41: 272-277.

14. Narayanan R, Kumar S, Gupta A, Bansal VK, Sagar S, et al. (2018) An analysis of presentation, pattern and outcome of chest trauma patients at an urban level 1 trauma center. Indian J Surg 80: 36-41. [Crossref]

15. Lavingia KS, Collins JN, Soult MC, Terzian WH, Weireter LJ, et al. (2015) Torso computed tomography can be bypassed after thorough trauma bay examination of patients who fall from standing. Am Surg 81: 798-801. [Crossref]

16. Waydhas C, Sauerland S: Thoracic trauma and chest tube (2003) Diagnostics and therapy - A systematic review. Notfall und Rettungsmedizin 7: 627-639.

17. Bokhari F, Brakenridge S, Nagy K, Roberts R, Smith R, et al. (2002) Prospective evaluation of the sensitivity of physical examination in chest trauma. Journal of Trauma 53: 1135-1138.

18. Kong VY, Sartorius B, Clarke DL (2015) The accuracy of physical examination in identifying significant pathologies in penetrating thoracic trauma. European Journal of Trauma and Emergency Surgery 41: 647-650.

19. Abdulrahman Y, Musthafa S, Hakim SY, Nabir S, Qanbar A, et al. (2015) Utility of extended FAST in blunt chest trauma: Is it the time to be used in the ATLS algorithm? World Journal of Surgery 39: 172-178. 
20. Saksobhavivat N, Shanmuganathan K, Boscak AR, Sliker CW, Stein DM, et al. (2016) Diagnostic accuracy of triple-contrast multi-detector computed tomography for detection of penetrating gastrointestinal injury: a prospective study. Eur Radiol 26: 4107-4120. [Crossref]

21. Saranteas T, Mavrogenis AF, Mandila C, Poularas J, Panou F (2017) Ultrasound in cardiac trauma. J Crit Care 38: 144-151. [Crossref]

22. Lacey RA, Monahan TS (2003) Correlation of clinical characteristics and outcomes with injury scoring in blunt cardiac trauma. The Journal of Trauma, Injury, Infection, and critical Care 54: v509-515.

23. Eghbalzadeh K, Sabashnikov A, Zeriouh M, Choi YH, Bunck AC, et al. (2018) Blunt chest trauma: a clinical chameleon. Heart 104: 719-724. [Crossref]

24. Steenburg SD, Ravenel JG, Ikonomidis JS, Schönholz C, Reeves S, et al. (2008) Acute traumatic aortic injury: imaging evaluation and management. Radiology 248: 748-762. [Crossref]

25. Arkarca FK, Korkmaz T, Cinar C, Cakal ED, Ersel M, et al. (2016) Evaluation of patients diagnosed with acute blunt aortic injury and their bedside plain chast radiography in the emergency department: A retrospective study. Ulusal travma ve acil cerrahi dergisi 22 : 449-456.

26. Kendall JL, Kestler AM, Whitaker KT, Adkisson MM, Haukoos JS (2011) Blunt abdominal trauma patients are at very low risk for intra-abdominal injury after emergency department observation. West J Emerg Med 12: 496-504. [Crossref]

27. Moura FHB, Parreira JG, Mattos T, Rondini GZ, Below C, et al. (2017) Ruling ou intra-abdominal injuries in blunt trauma patients using clinical criteria and abdominal ultrasound. Revista do Colegio Brasileira de Cirurgioes 44: 626-632.

28. Benjamin E, Cho J, Recinos G, Dilektasli E, Lam L, et al. (2017) Negative computed tomography can safely rule out clinically significant intra-abdominal injury in the asymptomatic patient after blunt trauma: Prospective evaluation of 1193 patients. Journal of Trauma and Acute Care Surgery 84: 128-132.

29. Firetto MC, Sala F, Petrini M, Lemos AA, Canini T, et al. (2018) Blunt bowe and mesenteric trauma: role of clinical sings along with $\mathrm{CT}$ findings in patients management. Emergency Radiology 25: 461-467.

30. Shah R, RamakrishnanM, Ahmed B, Abuamr K, Yousef O, et al. (2017) Perforated bladder as a cause of abdominal ascites in a patient presenting with acute onset abdominal pain. Cureus 9: 1241

31. Verbeek DO, Zijstra IA, van der Leij C, Pnsen KJ, van Delden OM, et al. (2014) Management of pelvic ring fracture patients with a pelvis blush on early computed tomography. Journal of Trauma and Acute Care Surgery 76: 374-379

32. Majidinejad S, Heidari F, Kafi Kang H, Golshani K (2018) Determination of Clinical Signs and Symptoms Predicting No Pelvic Fracture in Patients with Multiple Trauma. Advanced Biomedical Research 8: 109-112.

33. Bolt C, O'Keeffe F, Finnegan P, Dickson K, Smit V, et al. (2018) Straight leg elevation to rule out pelvic injury. Injury 49: 279-283. [Crossref]

34. Pehle B, Nast-Kolb D, Oberbeck R, Waydhas C, Ruchholtz S, et al. (2003) Significance of physical examination and radiography of the pelvis during treatment in the shock emergency room. Unfallchirurg 106: 642-648.
35. Shlamovitz GZ, Mower WR, Bergman J, Chuang KR, Crisp J, et al. (2009) How (un) useful is the pelvic ring stability examination in diagnosing mechanically unstable pelvic fractures in blunt trauma patients? Journal of Trauma 66: 815-820.

36. Zwingmann J, Lefering R, Maier D, Hohloch L, Eberbach H, et al. (2018) Pelvic fractures in severely injured children: Results from the TraumaRegister DGU. Medicine (Baltimore) 97: e11955. [Crossref]

37. Tanizaki S, Maeda S, Ishida H, Yamamoto T, Yoshikawa J (2017) Clinical characteristic of external iliac artery branch injury in pelvic trauma. Am J Emerg Med 35: 1636-1638. [Crossref]

38. Solai CA, Domingues CA, Nogueira LS, de Sousa RMC (2018) Clinical signs of basilar skull fracture and their predictive value in diagnosis of this injury. Journal of Trauma Nursing.

39. Van Leeuwen N, Lingsma HF, Perel P, Lecky F, Lu J, et al. (2012) Prognostic value of major extracranial injury in traumatic brain injury: An individual patient data metaanalysis in 39274 patients. Neurosurgery 70: 811-818.

40. Fuller GW, Evans R, Preston L, Woods HB, Mason S, et al. (2018) Should adults with mild head injury who are receiving direct oral anticoagulants undergo computed tomography scanning? A systematic review. Annals of Emergency Medicine.

41. Inaba K, DuBose JJ, Barmparas G, Barbarino R, Reddy S, et al. (2011) Clinica examination is insufficient to rule out thoracolumbar spine injures. Journal of Trauma 70: $174-179$.

42. Morgenstern M, von Rüden C, Callsen H, Friedrichs J, Hungerer S, et al. (2016) The unstable thoracic spine cage injury: The concomitant sternal fracture indicates a severe thoracic spine fracture. Injury 47: 2465-2472.

43. Jacob M, Hassager C, Bro-Jeppesen J, Ostrowski SR, Thomsen JH, et al. (2015) The effect of targeted temperature management on coagulation parameters and bleeding events after out-of-hospital cardiac arrest of presumed cardiac cause. Resuscitation 96: 260-267.

44. Lawrence MJ, Marsden N, Mothukuri R, Morris RH, Davies G, et al. (2016) The effects of temperature on clot microstructure and strength in healthy volunteers. Anesthesia and Analgesia 122: 21-26.

45. Lier H, Bottiger BW, Hinkelbein J, Krep H, Bernhard M, et al. (2011) Coagulation management in multiple trauma: a systematic review. Intensive Care Medicine 37: 572582

46. Differding JA, Underwood SJ, Van PY, Khaki RA, Spoerke NJ, et al. (2011) Trauma induces a hypercoagulable state that is resistant to hypothermia as measured by thrombelastogram. Am J Surg 201: 587-591. [Crossref]

47. Meyer MA, Ostrowski SR, Overgaard A, Ganio MS, Secher NH, et al. (2013) Hypercoagulability in response to elevated body temperature and cetral hypovolemia. Journal of Surgical Research 185: 93-100.

48. Strudwick K, McPhee M, Bell A, et al. (2018) Review article: Methodology for the 'rapid review' series on musculoskeletal injuries in the emergency department. Emerg Med Australas 30: 13-17. [Crossref]

49. Stinner DJ, Edwards D (2017) Surgical Management of Musculoskeletal Trauma. Surg Clin North Am 97: 1119-1131. [Crossref]

50. German Society of Trauma Surgery (DGU) (2016) S3 guidelines on treatment of polytrauma/severe injuries. AWMF, 01.07.2016.

Copyright: (C2018 Pliske G. This is an open-access article distributed under the terms of the Creative Commons Attribution License, which permits unrestricted use, distribution, and reproduction in any medium, provided the original author and source are credited. 